\title{
JUAN DE PITANO Y BOLÍVAR, PLATERO VITORIANO DEL SIGLO XVI
}

\author{
POR \\ ROSA MARTÍN VAQUERO \\ Doctora en Historia del Arte
}

Juan de Pitano y Bolívar is one of the most important silversmiths of the second half of the 16th century in Vitoria. He was the successor to one of Vitoria's oldest silversmiths which had its origins in the previous century. Here we provide a biography of the man and present ten pieces of his work in which we are able to appreciated their quality together with the artistic techniques employed. All of the pieces bear his mark: PI/ TANO. He was a master of his art and participated in all three of the styles which dominated the art of the silversmith in the 16th century: Gothic, Renaissance and Mannerism.

Juan de Pitano es, sin duda, uno de los más importantes plateros vitorianos de la segunda mitad del siglo XVI. Pertenece a una de las familias más destacadas que ejercieron el arte de la platería en la ciudad y cuyos miembros más antiguos hunden sus raíces en el siglo anterior. El primer platero que conocemos con este nombre es Juan de Pitano, documentado en 1436, al que seguirán otras dos generaciones con su mismo nombre ${ }^{1}$. A éste le continuarán en el oficio dos de sus hijos Juan y Martín. De Juan desconocemos el año de su nacimiento, aparece casado con Juana de Bolívar en 1523, de este matrimonio nace un hijo -Juan- que seguirá con el oficio y del que aquí nos ocuparemos ${ }^{2}$. Su hermano Martín nace en 1495 y muere en $1555^{3}$. Está casado en 1540 con Catalina López de Corcuera ${ }^{4}$ y tienen dos hijos, a saber: Martín, nacido en 1544 y del que no tenemos constancia de que siguiera con el oficio ${ }^{5}$; y Ana, que se casa con el también platero vitoriano Juan de Erenchun ${ }^{6}$.

El platero Juan de Pitano y Bolívar, está casado con María Ortiz de Zárate y viven en la calle

1 Portilla Vitoria, M. J. y otros: Catálogo Monumental. Diócesis de Vitoria. Ciudad de Vitoria, t. III, Vitoria, 1971, pp. 64 y 77.

2 A. P. San Miguel. Vitoria. Lib. Bautizados (1578-1677), s/f. Aparecen apadrinando a un hijo del también platero Juan de Erenchun.

3 En la sesión de 6 de febrero de 1555 comparece, Diego de Rejarte que tenía el cargo del sello de la plata junto con Martín de Pitano «que sea en gloria»: A.M.V.Lib. Acuerdos (1549-1557), núm. 15, Secc. 12, leg. 7, f. 216 v.

${ }_{4}$ Aparece como testigo junto a su mujer en un pleito llevado a cabo por el platero Vitoriano Martín de Erenchun: A.R.CH.V. Secc. Pleitos Civiles. Esc. Lapuerta (F). Sig. C 2621/2.

5 A.H.P.A. Esc. Esteban de Isunza. Prot. 6658, s/f. Escritura de aprendizaje de 13 de marzo de 1544. En este documento firma como testigo Martín de Pitano, en la que se dice que es hijo de Martín de Pitano, platero.

6 En la iglesia de San Vicente de Vitoria, en 1557 es bautizada María, hija de Juan de Erenchun y de Ana de Pitano: A. P. San Vicente. Vitoria. Lib. Bautismos (1524-1564), núm. 1, f. 34 v. 
Correría de la ciudad ${ }^{7}$. Tienen cuatro hijos: Justa, Martín, que nace en 1560, Catalina, en 1563 y Francisca $1578{ }^{8}$. Aparece documentado desde c.1545 y muere en 1594. Su hija Justa se casa con el platero Pedro de la Fuente, que a la muerte de su suegro, le sucede en el cargo de contraste de la ciudad que éste ejercía 9 . Del platero Juan de Pitano, hemos recopilado un importante número de datos relacionados tanto con su vida como con su actividad artística. A través de estos documentos podemos conocer como era la vida de este artífice, su posición social y económica, las relaciones sociales que mantenía, y lo que es más importante, las obras que hacía, aunque la producción que actualmente se conserva es una mínima parte (fig. 1).

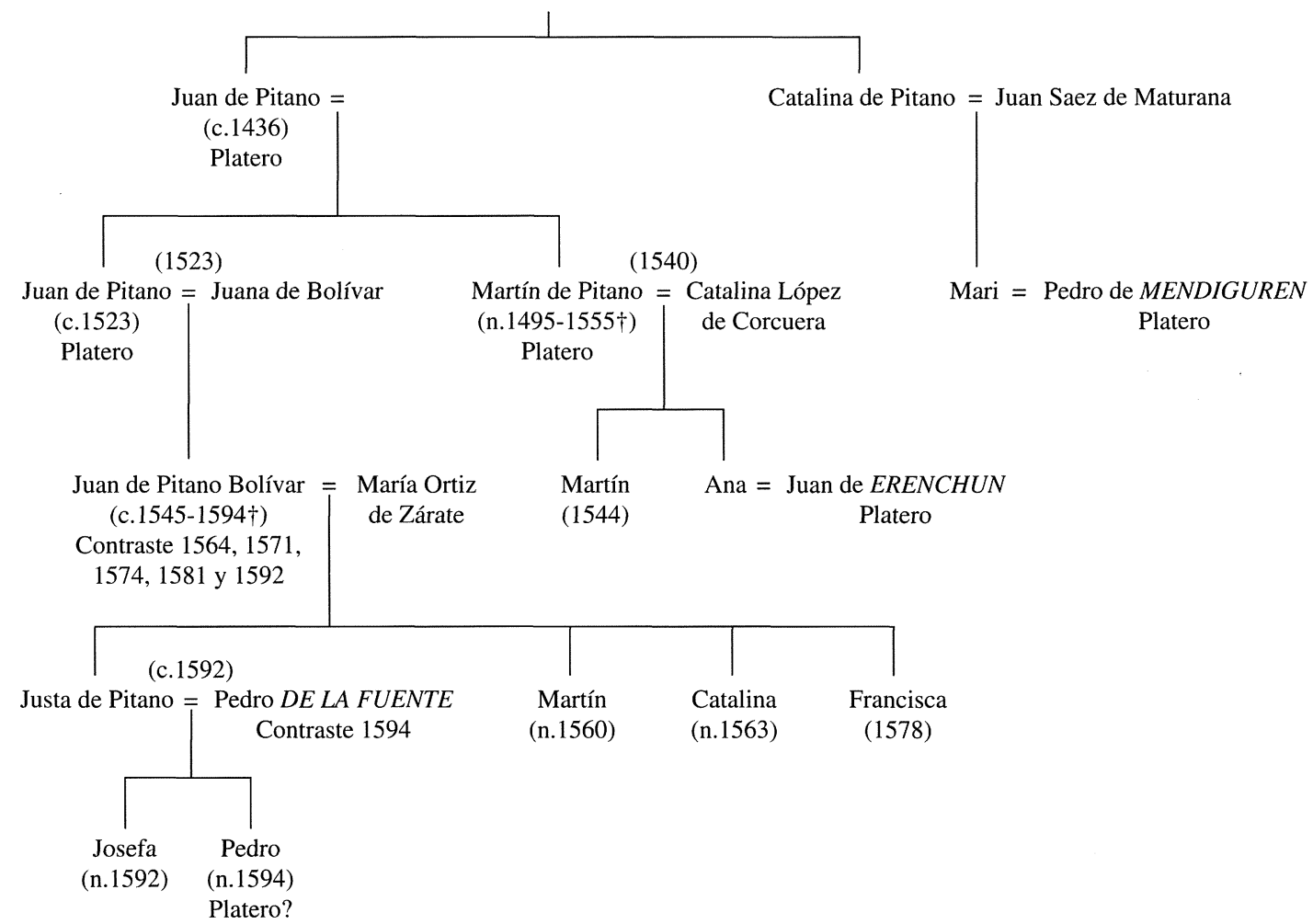

Fig. 1. Generación de la familia Pitano. Entronque con las familias: Mendiguren, Erenchun y de la Fuente.

Los datos concernientes a su vida son documentos en los que figura como testigo en pleitos y herencias, apadrinando - tanto él como su mujer- a varios hijos de otros plateros que trabajan en la ciudad. Pago de Alcabalas, que nos informan del lugar donde vive y lo que le corresponde pagar; consultas de particulares llamados por el Ayuntamiento de la ciudad para resolver algunos asuntos. A veces, compra o vende cosas y soluciona problemas familiares. Los relacionados con su actividad artística, se refieren a escrituras de contratos de obras a realizar, reparos y aderezos de piezas; y otros relativos al cargo de fiel marcador y contraste de la ciudad que ejerció en varias ocasiones.

7 A.G.S. Secc. Expedientes de Hacienda. Leg. 203, f. 192-206. Padrón de vecinos de la ciudad de Vitoria de 1577.

8 A. P. San Miguel. Vitoria. Lib. Bautizados (1578-1677), s/f.

9 A.M.V. Lib. Acuerdos (1590-1594), núm. 24. Secc. 14, leg. 18, f. 274 r y v. Es nombrado junto a Martín Ruiz de Alegría, por muerte de Juan de Pitano, su suegro. 
Las primeras noticias sobre su vida -como padrino de bautismos o bodas-, nos proporcionan además los nombres de los plateros activos en ese momento en la ciudad, así como las relaciones que entre los distintos miembros del mismo oficio existían. Estas noticias nos llevan a pensar que gozaba de buena posición y del aprecio de los miembros de su oficio. El 5 de mayo de 1559, es padrino de Diego, hijo de Salazar - platero- y de María de Zurbano ${ }^{10}$. El 26 de octubre 1560, María de Zárate, mujer de Juan de Pitano es madrina de Gerónima hija del platero Salazar y de María de Zurbano ${ }^{11}$; el 6 de enero de 1577, lo es de María hija de Pedro de Zaldivia - platero- y de María Nadea Armentia ${ }^{12}$ y el 21 de marzo de 1581, lo es de Mariana, hija de Andrés de Lazcano - platero- y de Cecilia Bedía ${ }^{13}$. El 16 de septiembre de 1585, su mujer es madrina de María, hija de Juan de Erenchun - platero- y de María de Zaldivia 14; y el 13 de junio de 1599, ya viuda, es madrina de Elena, hija de Antonio de Amárita - platero- y de Francisca González de Gauna ${ }^{15}$.

Según una lista inserta por el Juez comisionado por S. M., para el pago de Alcabala, elaborada a partir del Padrón de vecinos de la ciudad de 1577, podemos comprobar que vivían en la calle de la Correría ${ }^{16}$. En 1583 vende unas casas que tiene en la calle de la Correría, como Juros de Heredad al capitán Cristóbal de Villalba, vecino de la ciudad, los funda sobre las dichas casas y sus pertenencias y dos huertas que tiene junto a ellas en dicho lugar, por 2.400 maravedíes de censo de la moneda corriente y usual de Castilla, cada año, sobre un monte de 31.586 maravedíes. Se especifica que si un año por mala cosecha, piedra, granizo, etc., "... se pague menos y cuando sea buena la cosecha se supla lo no pagado" ${ }^{17}$.

El 12 de enero de 1593, es llamado a consulta por el Ayuntamiento de la ciudad, junto a otros particulares, para deliberar en asuntos de la ciudad lo que mejor convenía al servicio de Dios Nuestro Señor y de su Majestad y el día 15 de enero aparece en una lista de vecinos reunidos a Concejo abierto ${ }^{18}$. Estas personas llamadas por el Ayuntamiento tenían que ser de buena reputación, de vida ejemplar y buenas costumbres con una economía considerable. No siempre en estas consultas nos encontramos personas que ejercían este oficio, frecuentemente son los señores de la pequeña nobleza -caballeros, escribanos y personas consideradas- los que figuran en estas listas.

Juan de Pitano Bolívar, es nombrado por los señores Regidores del Ayuntamiento de la ciudad, en varias ocasiones, Fiel marcador de los plateros. Cargo muy importante para los plateros porque se le consideraba el mejor platero de la ciudad, además solamente podían ejercer este cargo, aquellos que gozaban de considerable reputación y buenas costumbres. Fue elegido, por primera vez, en la sesión del 7 de enero de 1564, junto con el platero Hernando Ochoa de Alegría, sustituyendo a Diego de Rejarte y Antonio de Junguitu. Les fue entregada la caja y marco de la dicha ciudad e hicieron el juramento acostumbrado con toda solemnidad ${ }^{19}$.

Posteriormente es elegido en otras cuatro ocasiones. En la sesión del Ayuntamiento de 12 de agosto de 1571, se vuelve a aludir a que según costumbre en esta ciudad, cada año se nombren en el oficio de plateros, veedores y marcadores y en estos años no se han nombrado, acor-

\footnotetext{
10 A.H.D.V. San Ildefonso. Vitoria. Lib. Bautismos (1551-1649), núm. 1, f. 29 v.

11 A.H.D.V. San Ildefonso. Vitoria. Lib. Bautismos (1551-1649), núm. 1, f. 195 v.

12 A. P. San Miguel. Vitoria. Lib. Bautizados (1578-1677), f. 5 v.

13 A.H.D.V. San Pedro. Vitoria. Lib. Bautismos (1550-1612), núm. 1, f. 88 r.

14 A. P. San Miguel. Vitoria. Lib. Bautizados (1578-1677), s/f.

15 A.H.D.V. San Vicente. Vitoria. Lib. Bautismos (1587-1648), f. 114 v. Como se puede comprobar por las noticias aquí recogidas, esta familia de artífices plateros mantenía buenas relaciones con casi todos los maestros plateros que trabajaban en ciudad en aquel momento.

16 A.G.S. Secc. Expedientes de Hacienda. Leg. 203, f. 171-191.

17 A.H.P.A. Esc. Jorge de Aramburu. Prot. 6218, f. 818 r. Firma como testigo el platero Juan de Erenchun.

18 A.M.V. Lib. Acuerdos (1590-1594), núm. 24. Secc. 14, leg. 18, f. 185 r.

19 A.M.V. Lib. Acuerdos (1561-1565), núm. 17. Secc. 12, leg. 5, f. 353 v.
} 
daron y mandaron "que se haga este año y en adelante lo sean Juan de Pitano y Sebastián de Zaldivia, los cuales fueron llamados a dicho Ayuntamiento y le entregaron la caja y marca, y hicieron la solemnidad del juramento conforme a derecho y buen estilo de hacer bien y fielmente el dicho oficio y cargo, hasta que por esta ciudad sea mandado" ${ }^{20}$. En 1574 los señores del Ayuntamiento reciben como veedores de los plateros y marcadores de la plata a Juan de Pitano, que le dieron la caja donde está el sello y a Martín Ruiz de Gauna como proveedor de la plata que se labrara en la ciudad. Ambos plateros vecinos de la ciudad, a los cuales el señor Alcalde tomó juramento como veedores de la plata, de que lo harán bien y fielmente sin falta ni quiebra alguna con toda rectitud y fieldad. Ellos prometieron así cumplirlo ${ }^{21}$.

De nuevo el 19 de mayo de 1581 le vuelven a confirmar en el cargo de fiel de los plateros junto con Martín Ruiz de Alegría, por el tiempo que fuere voluntad de la ciudad ${ }^{22}$. El 20 de enero de 1592 es nombrado, de nuevo, por los señores del Regimiento de la ciudad fiel de platería, junto con Martín Ruiz de Alegría. Le fue tomado juramento por el Alcalde y le entregaron la arquilla con los elementos precisos para el dicho oficio, y ellos lo recibieron y se ofrecieron de dar cuenta de todo ello ${ }^{23}$. El 25 de febrero de 1594 son nombrados nuevos marcadores -Martín Ruiz de Alegría y Pedro de la Fuente- para la plata que se labra en la ciudad, se dice "por muerte de Juan de Pitano" ${ }^{24}$.

Su actividad artística, a juzgar por las piezas recogidas y por las que se mencionan en los documentos, fue muy importante. Hemos recopilado un gran número de contratos de obras -cruces, cálices, incensarios, lámparas, etc.-, las cuales, hoy por desgracia, no se conservan. También relacionados con su profesión tenemos numerosos pagos por aderezos y arreglos de piezas efectuados para diferentes iglesias.

En las cuentas de la Fábrica de la iglesia Colegial de Santa María de Vitoria, en 1559, le pagan ocho reales por soldar la calderilla del incensario y limpiarlo, y por aderezar la naveta a la que le puso tres reales de plata ${ }^{25}$. En 1565 , le vuelven a pagar doscientos setenta y dos maravedíes por aderezar el incensario ${ }^{26}$. En 1560-66 hace para la iglesia de Munain, un incensario de plata y una custodia ${ }^{27}$. En 1572 y 1574 trabaja en diversos arreglos para la iglesia de San Miguel de Vitoria: en 1572, adereza las vinajeras de plata que estaban quebradas, le pagan doscientos cuarenta y dos maravedíes y le entregan, además, tres reales de plata, y en 1574 el mayordomo Juan de Aramburu, le paga por aderezar un cáliz que estaba roto 28 .

El 11 de septiembre de este mismo año, se obliga a hacer una cruz de plata para la iglesia de Imiruri (Treviño). El ajuste lo hace Francisco de Loste, clérigo de la iglesia del lugar de Imiruri y el platero Juan de Pitano, vecino de la ciudad. Entre las condiciones se alude a que ha de ser «a la manera de la cruz que ha hecho para la iglesia de Elguea, con el mismo modelo y facciones de ella», y se compromete a entregarla para San Juan de junio del año próximo 29.

El 7 de mayo de 1579 contrata otra obligación de hacer una cruz de plata para la iglesia de San Andrés de Elosu (Álava). El ajuste lo hace con Juan de Abad de Galarza, clérigo y beneficiario de la iglesia del lugar de Anzuola, jurisdicción de la Villa de Vergara y Miguel de Aguirre Zaval vecino de la Villa de Vergara como mayordomos que son de la iglesia de San Andrés de

20 A.M.V. Lib. Acuerdos (1569-1573), núm. 19. Secc. 12. leg. 3, f. 317 v.

21 A.M.V. Lib. Acuerdo (1573-1578), núm. 20. Secc. 12, leg. 2, f. 159 v.

22 A.M.V. Lib. Acuerdos (1578-1582), núm. 21. Secc. 12, leg. 1, f. 510 r.

23 A.M.V. Lib. Acuerdos (1590-1594), núm. 24. Secc. 14, leg. 18, f. 135 r. y v.

24 A.M.V. Lib. Acuerdos (1590-1594), núm. 24. Secc. 14, leg. 18, f. 274 r. y v.

25 A.C.C. Colegial de Santa María. Vitoria. Lib. Fábrica (1537-1590), núm. 234, f. 91 v.

26 A.C.C. Colegial de Santa María. Vitoria. Lib. Fábrica (1537-1590), núm. 234, f. 115 r

27 A.H.D.V. Munain. Lib. Fábrica (1524-1680), núm. 4, f. 77 v. y 88 r. El coste de estas piezas le fue abonado en 1570.

28 A. P. San Miguel. Vitoria. Lib. Fábrica (1552-1678), f. 41 r. y 44 r.

29 A.H.P.A. Esc. Jorge de Aramburu. Prot. 6201, f. 860 r. Cfr. Portilla Vitoria, M. J. y otros: Catálogo Monumental..,, ob. cit., t. III, pág. 77. 
Elosu. Entre las condiciones se dice que ha de llevar un Crucificado, y que se entregará para el día de San Miguel, sin otro plazo ${ }^{30}$.

El 27 de septiembre de 1580, hace de nuevo otra escritura obligación por la que se compromete a realizar una cruz de cobre para la iglesia de San Miguel de la ciudad de Vitoria. Se ajusta con Juan Ortiz de Latierro, clérigo, cura de la iglesia del lugar de Undona. Se obliga a pagar al dicho Juan Pitano por «el oro, cobre, plata y hechuras» y le exige sea entregada para el día de San Juan de junio ${ }^{31}$. En las cuentas de Fábrica de la iglesia de San Miguel (Vitoria) de 1592, el mayordomo Juan de Palacio, le paga dieciocho reales por la naveta que hizo para el incensario de plata ${ }^{32}$. Los contratos de obras mencionados aparecen avalados con su firma (fig. 2).
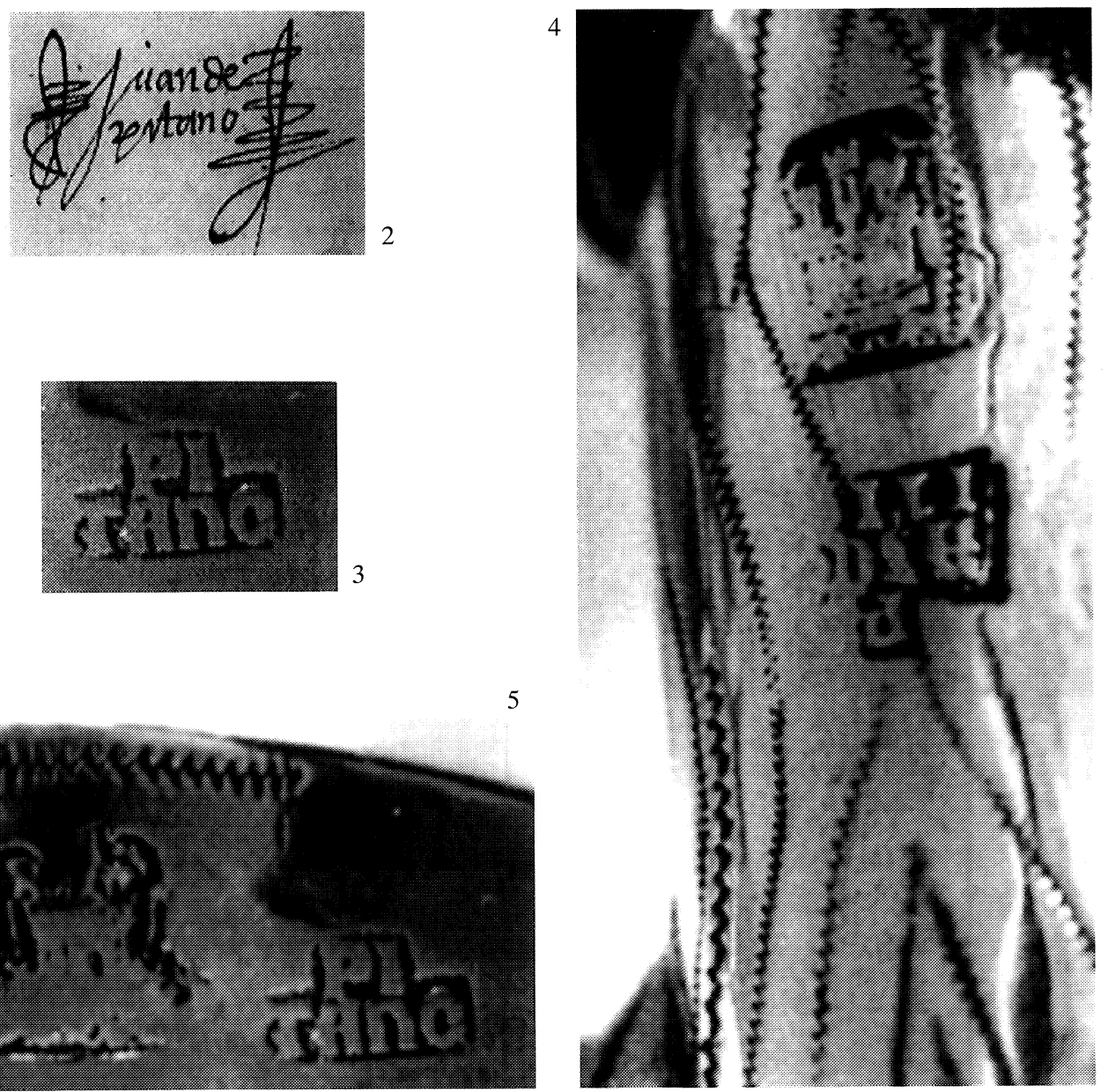

Fig. 2. Firma del platero vitoriano Juan de Pitano.

Fig. 3. Marca del platero vitoriano Juan de Pitano. Pixide de Hereña (Álava).

Fig. 4. Marca de la ciudad de Vitoria (punzón C) y del platero Juan de Pitano. Burilada. Cruz de nudos de Zumárraga (Guipúzcoa M.D.SS.)

Fig. 5. Marca de la ciudad de Vitoria (punzón D) y del platero Juan de Pitano. Burilada. Patena de Asteguieta (Álava).

30 A.H.P.A. Esc. Jorge de Aramburu. Prot. 6880, f. 222 v. Cfr. Portilla Vitoria, M. J., y otros: Catálogo Monumental.., ob. cit., t. III, pág. 77.

31 A.H.P.A. Esc. Jorge de Aramburu. Prot. 6212, f. 598 r. Cfr. Portilla Vitoria, M. J. y otros: Catálogo Monumental.., ob. cit., t. III, pág. 77.

32 A. P. San Miguel. Vitoria. Lib. Fábrica (1552-1678), f. 100 r. 
En cuanto a la producción artística que se conserva, realizada por este platero, hemos logrado reunir diez excelentes piezas, en las que lleva estampada la marca personal que utilizó: PI/ TANO -su apellido en letras góticas y en dos líneas-. Afortunadamente, Juan de Pitano Bolívar, es un platero que tenía por costumbre marcar las piezas que labraba, de ahí que una vez identificado su punzón personal hallamos podido conocer sus obras ${ }^{33}$. En tres de las piezas se acompaña además con la marca de la ciudad - castillo sobre dos leones y dos cuervos en las almenas, identificado por nosotros como punzón $\mathrm{C}$ y $\mathrm{D}-\mathrm{y}$ una pequeña burilada. Pensamos que en este caso él mismo actuó como artífice y como marcador, ya que como nos hemos referido, ejerció este cargo en varias ocasiones 34 (figs. 3, 4 y 5).

La formación artística de este platero, por las fechas en que constatamos su actividad, tuvo que realizarse en la segunda década del siglo xvi, en el taller familiar junto a su padre ${ }^{35}$. A partir del segundo cuarto del siglo las formas góticas van a ser sustituidas por las renacentistas, siendo los motivos decorativos los primeros que se implantaron en las obras. Esto lo podemos apreciar en la tipología y modelos decorativos de las primeras piezas realizadas por este platero, en las que se acusa una fuerte tradición gótica.

El platero Juan de Pitano fue un hombre anticipado en su época, adoptó tempranamente las tendencias más avanzadas de la orfebrería, participando de las corrientes del momento. A través de la piezas que aquí recogemos podemos apreciar la evolución artística de este artífice que participó de los tres grandes estilos artísticos de la orfebrería del siglo xvI: Gótico, Renacimiento y Manierismo.

Las piezas que presentamos responden a una tipología variada: una cruz de nudos de Zumárraga, una píxide de Hereña, los cálices de Landa, Gaceo, Ogueta, Mallavia y otro de colección particular, las patenas de Asteguieta, Mallavia y Caicedo-Sopeña y unas crismeras de colección particular. Todas ellas con la marca personal del platero, en la cruz de nudos de Zumárraga, en el cáliz de Ogueta y en la patena de Asteguieta, se acompaña con la marca de la ciudad y una pequeña burilada.

La cruz de nudos de la iglesia de la Asunción de Zumárraga (Museo Diocesano de San Sebastián), es la pieza más antigua que hemos recogido de este platero. Está realizada en plata en su color y el Crucificado sobredorado, mide $51 \times 37 \mathrm{~cm}$. Lleva estampadas entre la decoración del árbol dos marcas: el punzón personal: P./TANO - remarcado dos veces- y la marca de la ciudad de Vitoria, se acompaña de una larga burilada. Carece de macolla y pie (figs. 6 y 7).

En su estructura, sigue el esquema-tipo de las cruces de nudos góticas. Responde al modelo de cruz latina de brazos cilíndricos con arranques de troncos también cilíndricos, cortados a bisel y dispuesto en cuatro filas, tres grupos en cada lado del brazo horizontal, cuatro y cinco en el vertical. El árbol va todo él decorado con una fina línea en zig-zag, con dibujos que simulan las vetas de la madera. Los brazos se rematan simplemente con el corte a bisel al igual que los nudos. La unión con el pie, desaparecido, la hace con una amplia moldura cilíndrica con filete liso, y se continúa con una cuña para enmangar.

33 Lo hemos reproducido y dado a conocer en nuestro estudio: La platería en la Diócesis de Vitoria (1350-1650). Tesis Doctoral, leída el 9 de febrero de 1996. Facultad de Filología, Geografía e Historia de Vitoria-Gasteiz. En prensa.

34 Apoyamos esta atribución, en las quejas que los plateros vitorianos exponían a los señores Regidores de la ciudad de que al marcador no se le comprobaba la ley de la plata que utilizaba. Además los fieles marcadores nombrados el 9 de enero de 1568 se comprometen a poner sus marcas y señales junto a las de la ciudad: A.M.V. Lib. Acuerdos (15651569), núm. 18. Secc. 12, leg. 4, f. 114 v.

35 El aprendizaje en el taller familiar parece que fue la norma más característica de la platería vitoriana, pues no tenemos constancia documental de aprendizaje de los hijos de los plateros activos en la ciudad. Conocemos escasos contratos de aprendizaje de plateros y éstos se refieren a aprendices de fuera del entorno familiar, o de otras poblaciones, como el de Francisco Barrón, vecino de Santo Domingo de la Calzada, en 1544, con Martín de Pitano, maestro platero, vecino de Vitoria: A.H.P.A. Esc. Esteban de Isunza. Prot. 6658, s/f. 
El Crucificado presenta buena factura, los brazos ligeramente arqueados, con el cuerpo vertical y paño ceñido de suaves pliegues en uve. La cabeza, de modelado muy fino, inclinada sin corona, con largos cabellos, barba y los ojos entornados. Detrás de la cual una moldura de cordoncillo en aspa rodea el crucero de la cruz. Encima del Crucificado tiene sobrepuesta una moldura con el INRI, que por su forma parece un añadido posterior a la cruz.

Las dos marcas que lleva estampadas se repiten, a ambos lados del brazo horizontal de la cruz (fig. 4). Se trata de la marca de localidad de Vitoria, -que nosotros definimos como punzón C: castillo sobre dos leones, con tres torres y dos cuervos sobre sus almenas. La segunda está remarcada y solamente aparece nítida la primera letra: P./...., pero la impronta que presenta creemos corresponde a Juan de Pitano, tiene también impresas dos buriladas. Se nos plantea la duda -como nos sucede en otras piezas- de si fue él el artífice que elaboró la pieza o si la marca estampada corresponde como marcador de la ciudad, pensamos que en este caso él fue el artífice. Conocemos otras dos piezas con la marca de este platero acompañada del sello de la ciudad, como el cáliz de Ogueta y la patena de Asteguieta (fig. 5).

La pieza sigue el modelo de cruces de nudos góticas que tendrán su apogeo en el último tercio del siglo xv y que gozará de una larga pervivencia -en la platería vitoriana- a lo largo de todo el siglo XVI ${ }^{36}$. En el aspecto decorativo, es de gran sobriedad, tal y como corresponde al estilo de este tipo de cruces de nudos, solamente el árbol presenta una esquemática ornamentación a base de líneas en zig-zag, imitando los troncos de la madera. Los largos nudos a bisel, nos indican un período avanzado en su realización, la podemos encuadrar en el segundo cuarto del siglo xvI. El modelado del Crucificado es de líneas finas con expresión de un Cristo muerto -característica que se impone en el período Gótico-, conserva aún la cordada en la cruz muy utilizada en este período.

En la iglesia de San Miguel de Hereña (Álava), hemos hallado una píxide de tipología gótica. Se trata de una caja cilíndrica, elaborada en plata en su color, mide $13 \mathrm{~cm}$. de altura total y la caja $3,8 \mathrm{~cm}$ y $9,2 \mathrm{~cm}$. de diámetro. Tiene el pie circular, de borde saliente plano y festoneado. En la base de la caja lleva estampado el punzón del artífice vitoriano: PI/TANO. Rodea la caja una inscripción gótica: «EN CORPUS MEUM» 37 (figs. 3 y 8).

Está decorada con varias estrias en la parte inferior y superior con cenefa de contarios que enmarca la inscripción central. La tapa en forma de torre cónica, algo abombada, se incrusta en el interior con borde igual que el de la caja, es lisa completamente y se remata en pequeña bola con cordoncillo en el centro. Lleva una pieza rectangular donde se inserta la cruz de remate, de brazos trenzados y terminaciones en flor de lis. Esta pieza es posible que no sea la original, al poderla cambiar con facilidad a veces se perdía y se le acoplaba alguna otra cruz de obras de otros períodos.

La marca del artífice no nos deja lugar a dudas en cuanto a su origen y por las peculiaridades anteriormente expuestas - motivos ornamentales y la no decoración en la tapa-, nos inclinamos a pensar que es un modelo característico de los talleres vitorianos, al que responden otras píxides conocidas sin marcas, como la de Antoñana (Álava) -ésta con inscripción también en la tapa. Al igual que la cruz de nudos, esta pieza por el modelo y la decoración que presenta, la podemos datar a mediados del siglo xvi.

El modelo muestra bastante similitud con los tipos burgaleses, sobre todo en el cuerpo cen-

36 En la platería vitoriana conocemos un importante número de cruces de nudos. La primera que tenemos documentada es de c.1493-1500, del platero burgalés Bernardino de Porres. Con marcas vitorianas, además de la aquí estudiada, tenemos otra cruz de mediados de siglo, con decoración renacentista, del platero vitoriano Sebastián de Zaldivia y documentada otra de finales de siglo, ésta ya con decoración manierista, realizada por el platero vitoriano Pedro de la Fuente. Otras tres son burgalesas y seis sin marcas.

37 Con esta misma inscripción y decoración conocemos otras píxides vitorianas sin marcas: una en el Depósito del Obispado de Vitoria y otras de las iglesias de Mesanza, Mártioda y Zárate. Cfr. Martín Vaquero, R.: La platería en la Diócesis..., ob. cit., piezas núms. 79, 95, 96 y 98. 

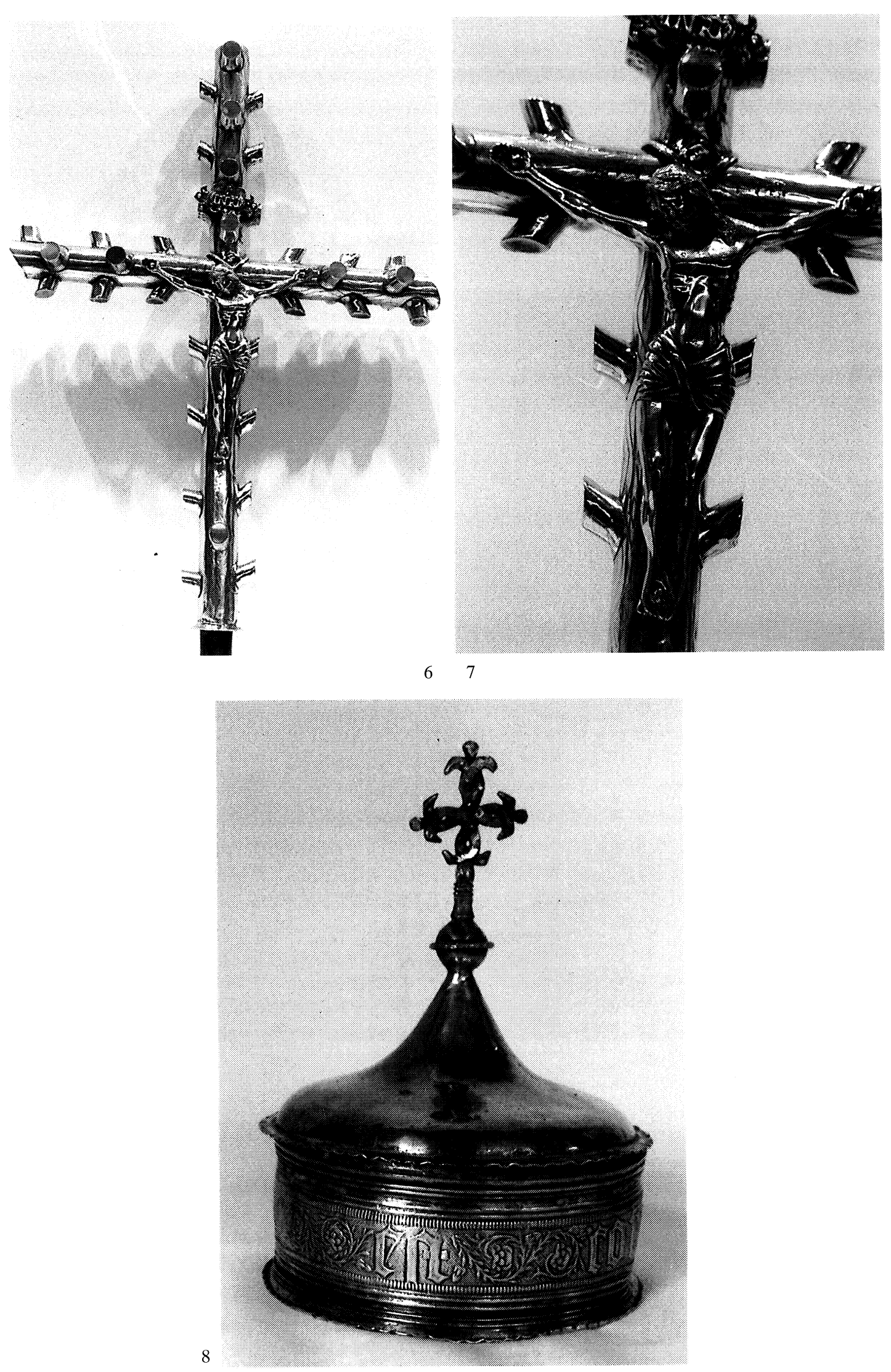

Figs. 6 y 7. Cruz de nudos. Zumárraga (Guipúzcoa. M.D.SS.). Siglo xvı. Segundo cuarto. Fig. 8. Píxide Hereña (Álava). Siglo xvi. Mediados. 
tral de la caja, aunque los pequeños dibujos que separan las palabras de la inscripción gótica que rodea la caja -todas ellas tienen florecillas y ramitos- son diferentes en las vitorianas. Tenemos como ejemplo las cajas de la píxide de San Vicente de Arana (Álava) y de Zárate (Álava) - de tipología muy similar - con marcas burgalesas. También varía ligeramente la altura de la tapa, que como la de Zárate no es tan cónica.

En los siglos xv y xvi hubo una gran demanda de este tipo de piezas que tenían un uso múltiple: como hostiario para guardar el Cuerpo de Cristo -como recuerda el epígrafe- en el Sagrario, y para llevar la comunión a los enfermos. Están elaboradas con una lámina de plata muy fina, son obras realizadas en serie, de escaso precio y de fácil elaboración. La decoración del friso es estampada. Debido a su bajo costo el modelo fue muy difundido y tuvo gran pervivencia.

Han llegado hasta nosotros cinco cálices con la marca de este platero: el cáliz de Landa, el de Gaceo, el de Ogueta, el de Mallavia (Vizcaya) y otro de colección particular (San Sebastián). En ellos podemos observar claramente la evolución estilística y decorativa de estas piezas a lo largo de la segunda mitad del siglo xvI.

El más antiguo es el cáliz de la iglesia de San Bartolomé de Landa (Álava). Es una soberbia pieza realizada en plata sobredorada, mide $21 \mathrm{~cm}$. de altura, $9,3 \mathrm{~cm}$. de diámetro copa y 17,8 $\mathrm{cm}$. de diámetro pie ${ }^{38}$. Lleva estampada la marca del platero: PI/TANO en uno de los lóbulos del pie. Alrededor de la peana presenta la siguiente inscripción: «ESTEC/ ALIZM/ ANDA/ RON.A.Z/ ER.JV ${ }^{\circ}$ D(E)/ ORVE.I/ M(A)RINaS/ MVGEr. Entre la decoración tiene grabado el escudo Franciscano con las Cinco Llagas. Su estado de conservación es regular, tiene el nudo deteriorado en la zona inferior donde se incrusta parte del astil, no obstante, se pueden apreciar las bellas proporciones de la pieza. Por los motivos ornamentales que presenta, podemos datarlo en el tercer cuarto del siglo xvi (figs. 9 y 10).

Se compone de un pie de perfil lobulado que se apoya en una pestaña lisa, tiene borde vertical con pequeñas molduras y cordón de esferillas entre ellas. La peana está decorada con ocho lóbulos, que tienden a juntarse, cuatro decorados profusamente y cuatro lisos, bordeados por una cinta lisa que resalta cada uno de ellos. La decoración a base de elementos renacentistas: animales fantásticos con cuerpos terminados en roleo, motivos vegetales, grandes hojas, ramos y jarrones. En dos de los lóbulos, entre la decoración, se simula una cruz de brazos abalaustrados, con terminaciones en roleos, y en la parte opuesta el escudo Franciscano sobre fondo granulado. La zona central está bordeada por una franja, a modo de cenefa circular, que recorre todos los lóbulos y alberga en su interior la inscripción citada. Se remata en una arandela saliente, decorada con pequeños botones abultados.

El astil está -en parte- deteriorado, al igual que el nudo en el que se introduce actualmente la parte primera del astil. Se puede observar que es un cuerpo cilíndrico y alargado de perfil cóncavo. El nudo de manzana achatada con una gran escotadura en la parte central, forma dos casquetes iguales con remates de arandelas salientes que se decoran con gallones abultados - con incisiones a modo de medias lunas- que se alternan con zonas lisas. Van todos ellos recercados por líneas incisas. En la parte superior se continúa con un cuello cóncavo - similar al de la parte inferior- en el que se puede apreciar gallones alargados y rehundidos, entre zonas lisas. La copa acampanada y lisa, muy abierta, con pequeña subcopa abullonada y decorada con gallones al igual que el nudo. Se remata con pequeña crestería de conchitas y perlas. Tiene estampada como se ha mencionado, una sola marca en uno de los lóbulos lisos del pie: PI/TANO, marca personal del artífice ${ }^{39}$.

\footnotetext{
$38 \mathrm{Al}$ estar deteriorado, no podemos apreciar las proporciones exactas de este cáliz, pese a estar bien labrado y ornamentado. Es una pena que no se hayan conservado otros modelos semejantes de este taller.

39 Esta impronta es la misma que aparece en el cáliz de Gaceo y en el cáliz de Ogueta, en este último junto con la de localidad de Vitoria, por ello pensamos que la misma impronta pudo utilizarla como artífice y como marcador.
} 
Los donantes, cuyos nombres aparecen en la inscripción son: Juan de Orbe y su mujer Mariana. El apellido, de linaje vasco, procede de Anguiotzar y Eibar (Guipúzcoa), tuvieron solar en Ermua. La dotación de una capilla o la devoción a alguno de los santos de una determinada iglesia, es el motivo más frecuente por el que cálices y otros utensilios de la liturgia religiosa se donaran a un determinado lugar. No nos constan los pormenores de estos donantes, pero como era habitual en la época dejaron sus nombres grabados para que no fueran olvidados en la posteridad.

El cáliz de la iglesia de San Martín de Gaceo, es de plata en su color, con el borde de la copa sobredorado. Mide $24 \mathrm{~cm}$. de alto, 10,2 cm. de diámetro copa y $15 \mathrm{~cm}$. de diámetro pie. A1 igual que el cáliz de Landa lleva estampada solamente la marca del platero: PI/TANO, en la parte interior del pie. Su estado de conservación es bueno (fig. 12).

Tiene el pie circular con pestaña de borde cóncavo. La peana formada por dos zonas: la exterior de perfil convexo con dos fajas cóncavas de borde inclinado, se adorna con gallones repujados de fondo rayado y recercados por dos líneas grabadas que los unen, en torno a una pequeña cruz abalaustrada. La zona interior se levanta sobre un borde recto al que sigue otro cónico con gallones rehundidos dirigidos hacía el astil, se remata con arandela saliente. El astil es hexagonal con dos cuerpos lisos, algo mayor el de la parte inferior, y el nudo en forma de manzana aplastada con friso cóncavo que lo divide en dos casquetes iguales con pequeñas molduras de remate. Está decorado, al igual que la peana, con gallones abultados finamente rayados y recercados, unidos mediante una cinta. La copa abierta y lisa, con pequeña subcopa abullonada y ornamentada con gallones, al igual que el nudo y el pie. Como remate dos pequeñas molduras redondeadas a modo de cenefa.

Desconocemos la fecha exacta de su realización por lo que debemos datarlo de acuerdo a los criterios estilísticos, que nos llevan a situarlo en el tercer cuarto del siglo. Podemos observar el cambio que el platero ha experimentado en la elaboración de este cáliz, en el que son predominantes los elementos renacentistas, frente a las reminiscencias góticas del cáliz anterior. Apreciamos como las estructuras góticas en algunos plateros vitorianos, como en este caso, es persistente pues el astil prismático de este cáliz nos pone de manifiesto la influencia que en la formación de este platero - hijo y nieto de plateros- tenían las formas antiguas. El nudo de manzana con gallones son elementos renacentistas más acorde con las formas de su época.

En la iglesia de San Andrés de Ogueta, tenemos un pie de cáliz - el astil y copa son posteriores-. Mide de diámetro $15,5 \mathrm{~cm}$. y lleva estampadas en la peana dos marcas: el escudo de la ciudad de Vitoria y PI/TANO, con una pequeña burilada en la parte interior (fig. 13). El pie es de perfil circular con pestaña plana y borde vertical, recorrido por una sarta de esferillas. La peana formada por dos zonas convexas, separadas por una moldura cóncava entre ellas. La exterior se decora con gallones abultados que se alternan con botones, ambos con fondo rayado que van bordeados y unidos por una doble línea grabada que termina, en ambos lados, formando dos bonitos roleos que se unen en torno a una cruz de brazos abultados con roleos grabados.

Las dos marcas estampadas, entre los gallones del pie, corresponden a la localidad de Vitoria - punzón C, castillo sobre dos leones con dos cuervos en las almenas- $(8 \times 8)$ y PI/TANO impronta del platero Juan de Pitano, acompañadas de burilada. Pensamos que es obra de su elaboración y a la vez actuó como marcador, pues parece que fue habitual en varias piezas vitorianas marcadas en este momento. El modelo tipológico que presenta y los motivos decorativos son característicos de este platero, por lo que creemos que él fue su artífice ${ }^{40}$.

40 Este cáliz se menciona: Portilla Vitoria, M. J., y Eguía López de Sabando, J.: Catálogo Monumental de la Diócesis de Vitoria. Arciprestazgos de Treviño y Campezo, Vitoria, 1968, t. II, pág. 148: «Cáliz. De plata repujada, con punzón del platero en el pie. Siglo XvII". 

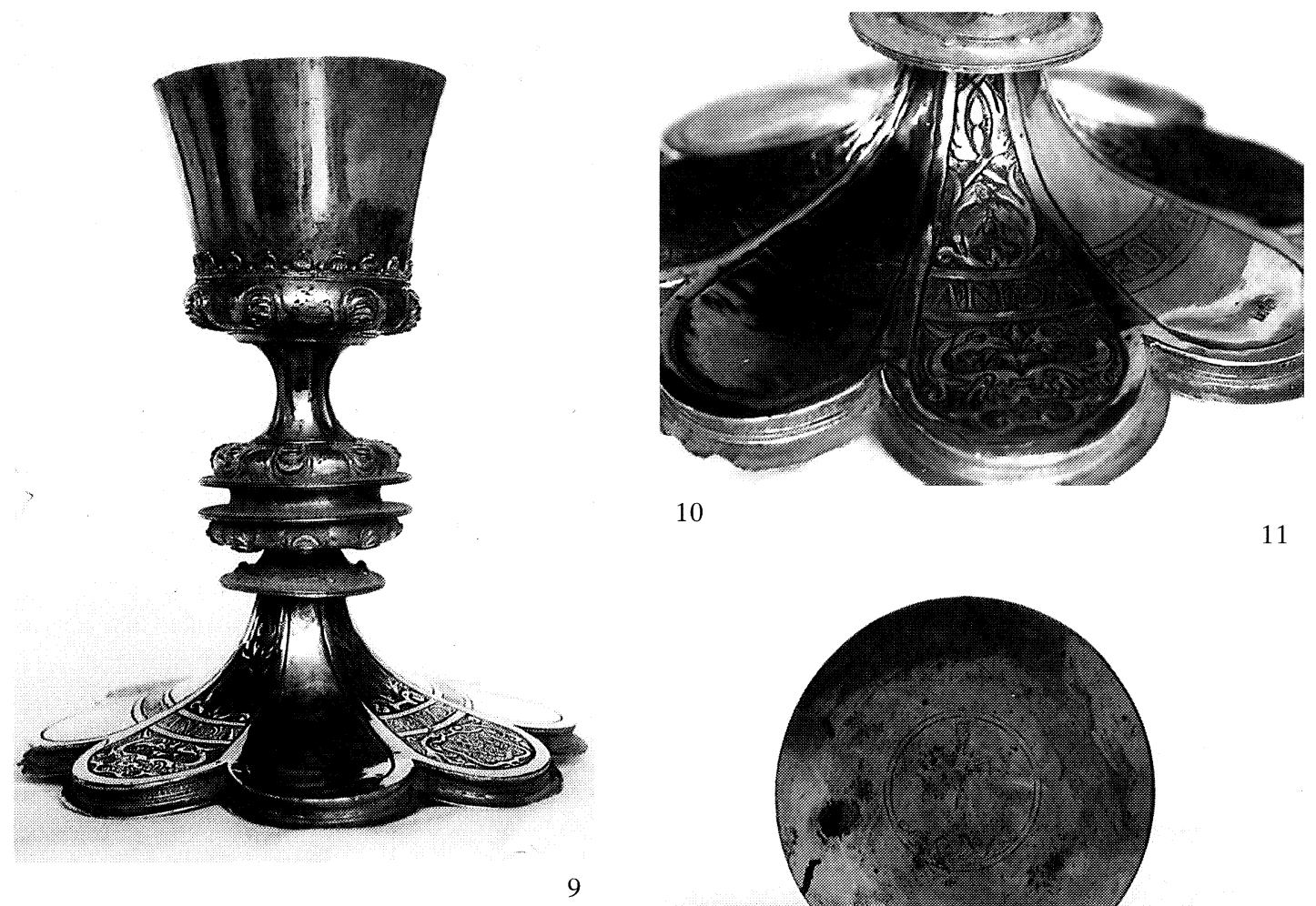

9

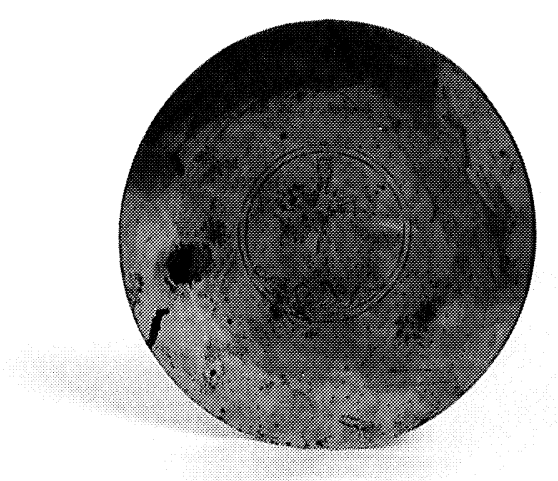

$12 \quad 13$
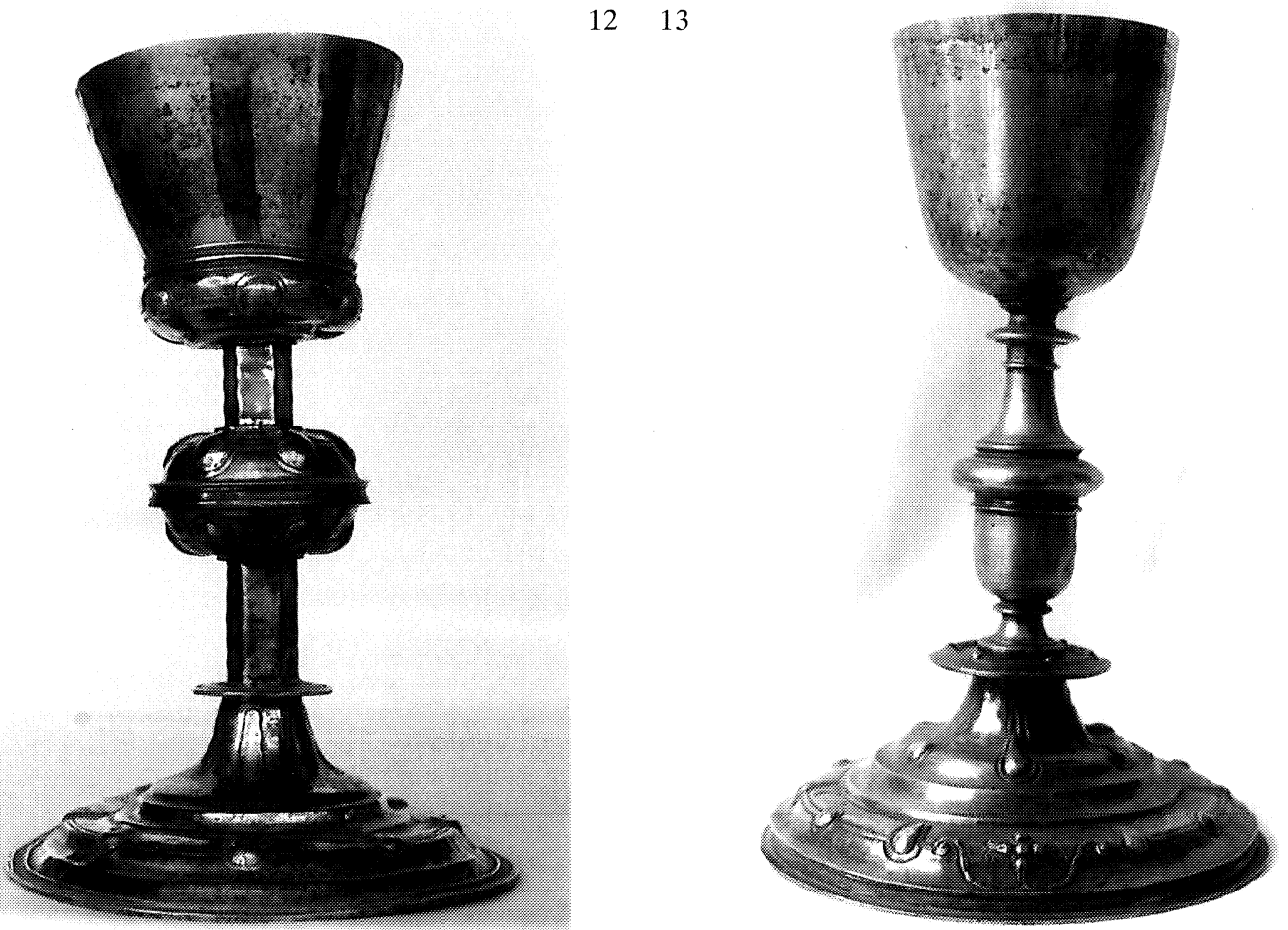

Figs. 9 y 10. Cáliz Landa (Álava). Siglo xvı. Tercer cuarto.

Fig. 11. Patena. Asteguieta (Álava). Siglo xvi. Último tercio.

Fig. 12. Cáliz, Gaceo (Álava). Siglo xvı. Tercer cuarto.

Fig. 13. Cáliz Ogueta (Ávila). Siglo xvi. Último tercio. 
El pie sigue, en su traza, el mismo esquema formal que ofrecía el cáliz anterior e insiste en utilizar la misma temática ornamental. Sin embargo, podemos apreciar algunos cambios estructurales que justifican su realización algo más tardía -tercer tercio del siglo-, podemos observar que ahora adopta la base circular ligeramente más amplia y elevada, aumentando más los cuerpos, y los motivos decorativos en resalte. Al no conservarse el astil y la copa original, nos impiden poder conocer la estructura de esta pieza.

El cáliz de la iglesia de la Asunción de Mallavia (Vizcaya), forma juego con una patena que lleva estampada la marca: PI/TANO. Por el modelo y motivos decorativos que presenta pensamos que fue realizado por el mismo artífice. Es de plata sobredorada, mide $26 \mathrm{~cm}$. de altura, $10,5 \mathrm{~cm}$. de diámetro boca y $16 \mathrm{~cm}$. de diámetro pie. Presenta una inscripción en el borde del pie en la que se lee: «ESTE CALIZ MANDARON HAZER JORGE DE VERANO BARRENHEGHEA I DONA MARI IVAN DE MALEAE SV MVGER 1582». Su estado de conservación es excelente (fig. 14).

Tiene el pie circular, con pestaña plana y borde vertical adornado con rosario de contarios entre finas molduras, motivo característico en los cálices de este artífice. La peana de dos zonas convexas, separadas por una fina escotadura lisa. En la zona inferior está recogida la inscripción aludida, en la que nos indica el nombre de sus donantes y el año -1582- en que debió realizarse. Se decora con óvalos abultados unidos por cintas lisas formando una cenefa en la que se alternan las superficies lisas con los fondos granulados y en el centro tiene una pequeña cruz con dos roleos. La zona superior, es ligeramente abombada, se decora a su vez con gallones recercados y finamente grabados, unidos a su vez por cintas que se alternan con espacios granulados entre ellos.

El astil se inicia con un gollete troncocónico, decorado con óvalos en resalte y sobre el que se asienta el nudo. Éste es ovoide y ligeramente abombado en el centro. Está, todo él, profusamente decorado, la parte inferior con los mismos motivos de gallones recercados y grabados que la zona inferior del pie, en el centro cintas entrelazadas lisas con fondos granulados y en la parte superior botones cóncavos. La copa es acampanada y lisa con friso de lustre que alterna con el bruñido del material, y la subcopa es bulbosa, con crestería de florecillas con botón central y adornada de gallones recercados y cintas lisas sobre fondo punteado, similares a los del pie.

Destaca en su decoración los gallones en las distintas partes de la pieza, abultados con fondos grabados y rehundidos en las partes cóncavas - gollete, nudo y cuello-. El cáliz es una pieza excepcional, lamentablemente no le hemos apreciado marcas - posiblemente por lo recargado de la decoración que no deja espacios libres-, pensamos no obstante, como hemos mencionado, que es obra del platero vitoriano Juan de Pitano. Son además varias las piezas que se conservan en Vizcaya y Guipúzcoa, con la marca de este platero por lo que parece gozaba de gran consideración y a él acudían los donantes para realizar sus encargos.

La pieza resulta doblemente interesante, por el modelo que presenta y por la exuberante decoración. Los motivos decorativos del friso de perlitas entre molduras y gallones abultados son muy empleados en las obras de este platero, pero en las piezas anteriores la decoración es más sencilla. La nueva estructura y decoración, representa la apertura hacia las nuevas corrientes. Esta abundante decoración también la podemos observar en el cáliz de colección particular, que estudiaremos a continuación. Como se puede apreciar la fecha de 1582, impresa en la inscripción, nos indica que es una obra de madurez realizada en sus últimos años -muere en 1594-. A través de esta pieza vemos como las tendencias manieristas imperantes en ese momento fueron bien asumidas por este artífice.

Relacionado con esta tendencia manierista tenemos también un cáliz de colección particular (San Sebastián). Está realizado en plata en su color, mide $22 \mathrm{~cm}$. de altura, $10 \mathrm{~cm}$. de diámetro copa y $15 \mathrm{~cm}$. de diámetro pie. Tiene estampada una sola marca borrosa que no podemos identi- 
ficar con seguridad. Se aprecia claramente la P./...., con una pequeña burilada, por el troquel que presenta, pensamos puede corresponder a la de nuestro artífice: PI/TANO ${ }^{41}$. Su estado de conservación es bueno (fig. 15).

Consta de un pie circular con borde vertical liso y zona plana. La peana formada por dos zonas convexas separadas por un pequeño borde liso. En la parte inferior se repujan gallones abultados entre una decoración burilada de tornapuntas y motivos geométricos simétricos, sobre un fondo punteado donde alternan los dibujos pulidos y con fondos recubiertos. La parte superior a base de gallones salientes recercados - más pequeños que los de la inferior-, se alternan con tarjetas rectángulos alargados, con fondo granulado y van enmarcados entre cenefa festoneada que bordea el perfil. Se remata con arandela saliente sobre la que se coloca un corto gollete cilíndrico con arandela volada.

El astil comienza con otro gollete troncocónico sobre el que se asienta el nudo semiovoide con cuello de jarrón. Está decorado con tres molduras, la inferior abultada con zona de gallones grabados y la superior con franja de motivos geométricos enlazados y simétricos que alternan las superficies lisas con fondos granulados. La copa acampanada y abierta es lisa, y la subcopa, marcada por una moldura abultada, semiesférica achatada, con decoración incisa a base de roleos hojas y tallos enlazados con botón central que simulan flores -al igual que la peana y el nudoentre fondo granulado. Como remate una fina moldura abultada de separación con la copa.

Este cáliz, al igual que el anterior, es obra de los último años, sigue las tendencias manieristas de la época con elementos y decoración de motivos geométricos, destacan las dimensiones de la copa y la originalidad de la subcopa. Podemos datarlo en el último cuarto del siglo.

Hemos recogido tres patenas que tienen estampada la marca de este artífice: la de Asteguieta, con la marca de la ciudad de Vitoria y una pequeña burilada y las de Mallavia y Caicedo-Sopeña, con el punzón del artífice solamente. Son las tres muy sencillas, presentando un pequeño dibujo las de Asteguieta y Caicedo-Sopeña, y lisa con anillos circulares grabados la de Mallavia. Las tres piezas siguen las características generales de este tipo de obras: simpleza de formas y la sencillez de la decoración.

La patena de la iglesia de la Natividad de Asteguieta, mide $14 \mathrm{~cm}$. de diámetro. Está realizada en plata sobredorada y presenta en el borde interior, las dos marcas anteriormente mencionadas -marca de la ciudad y personal del artífice-, con el mismo troquel que las del cáliz de Qgueta, por lo que podemos datarla, al igual que aquel, en el último tercio del siglo xvi (fig. 11). Es de forma circular, ligeramente cóncava. La parte exterior está decorada en el fondo con un anillo que incluye un motivo, a manera de medallón, que presenta una cruz latina que simula los cortes de la madera y cuatro puntas a modo de flameros, se asienta sobre una cenefa de roleos que simbolizan un monte. En la parte exterior, un anillo inciso marca un ancho borde, con fondo granulado, en el que tiene estampadas las marcas referidas.

La patena de la iglesia de San Martín de Caicedo-Sopeña, está realizada en plata sobredorada. Tiene $14,5 \mathrm{~cm}$. de diámetro y lleva estampada la marca de su artífice: PI/TANO. Es de perfil circular y ligeramente cóncava. La parte exterior está decorada, al igual que la anterior, con borde de lustre que resalta el brillo del resto de la pieza y en el fondo un anillo doble, inciso, a modo de medallón que aloja en su interior cuatro pétalos lisos, entre los brazos de una cruz de malta con los bordes festoneados. En la parte interior tiene estampada la marca. Desconocemos la fecha exacta de elaboración de la pieza, pensamos que es obra datable en el tercer cuarto del siglo XvI.

41 Tiene una pequeña burilada en el reverso del pie, pero no le hemos apreciado marca de localidad. No obstante una impronta muy semejante e imperfecta y con idéntica burilada es la que presenta estampada la cruz de nudos de $\mathrm{Zu}$ márraga, acompañada de la marca de localidad de Vitoria, por lo que creemos que esta pieza es obra vitoriana, de este platero. Con elementos similares tenemos otros cálices como el de Andagoya con la marca de la ciudad de Vitoria. 

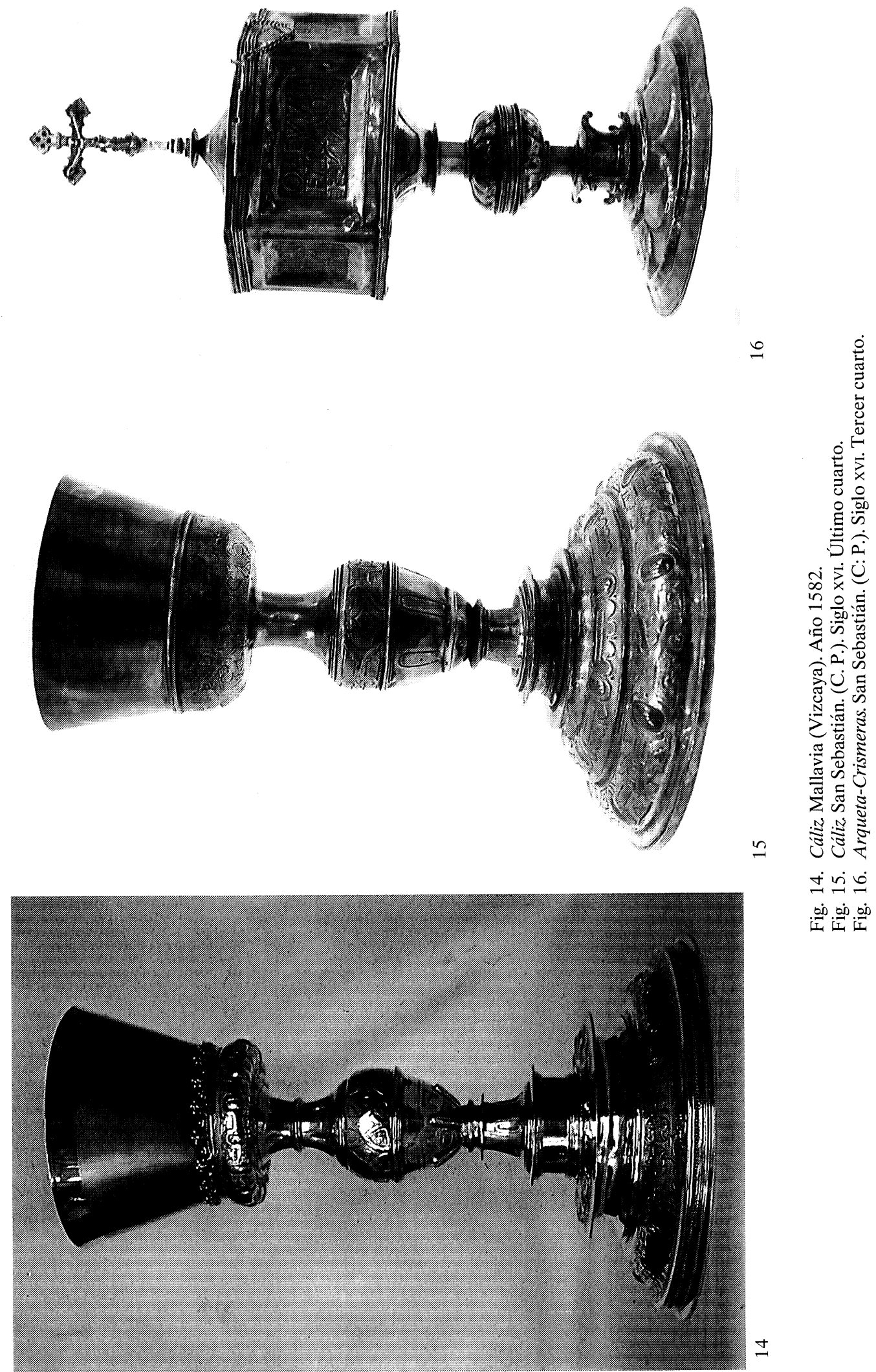
La patena de la iglesia de la Asunción de Mallavia (Vizcaya), alterna la plata en su color y sobredorada. Es de forma circular y ligeramente mayor que las dos anteriores, mide $16 \mathrm{~cm}$. de diámetro y lleva estampada una sola marca: PI/TANO, con igual troquel que la de Caicedo-Sopeña. En la parte cóncava lleva grabada una flor cuatripétala -con partes perdidas por la limpieza y el uso-. Forma juego con el cáliz de este mismo lugar con el que se acompaña. Por la inscripción del cáliz, en la que consta el año-1582- pensamos que se realizaría en torno a esa fecha.

En último lugar cerraremos este capítulo con una singular pieza, la arqueta-crismeras de colección particular (San Sebastián). Está realizada en plata en su color, mide $30 \mathrm{~cm}$. de altura y 14 $\mathrm{cm}$. de diámetro pie. Tiene estampada una sola marca, con la impronta remarcada y sobrepuesta. En las caras de la caja prismática donde se guardan los oleos presenta una inscripción en la que nos deja clara la función para la que fue realizada, se lee: OLEVN/SAN/TUN/ y CRI/SM/A (caras pequeñas) OLEVNI/FIRMO/RVN (cara grande). Su estado de conservación es bueno (fig. 16).

La pieza tiene pie circular con amplia pestaña inclinada y otra zona más elevada con el mismo perfil, se decora con seis lóbulos, resaltados por un pequeño borde, que alojan en su interior bustos de apóstoles con su atributo: San Pedro -llaves-, San Pablo - espada- y San Andrés -cruz en aspa-, se alternan con los otros tres lisos. El astil, de corte hexagonal, con un primer cuerpo cilíndrico moldurado con arandelas salientes y entre ellas lleva cuatro asitas que rematan en roleo. El nudo en forma de manzana achatada, tiene en la parte central friso cilíndrico con molduras que lo divide en dos casquetes semiesféricos y decorados, ambos, con gallones en resalte.

Sobre un cuerpo troncopiramidal invertido, se levanta la arqueta prismática hexagonal de caras rehundidas con remate de molduras, y adornadas - tres de sus caras- con las palabras aludidas referentes a su contenido. En la otra cara un ángel con alas y roleos. La tapa que la cubre tiene forma de talud, terminada en una pirámide que se decora con pequeños tondos que alojan en su interior cabezas de animales - cordero, toro y otros dos- que van enmarcados, a su vez, entre roleos y motivos vegetales. Como remate, sobre una arandela, tiene colocada una cruz latina de brazos rectos con expansiones y terminaciones treboladas con la imagen del Crucificado.

La marca impresa en el pie presenta la impronta bastante borrosa, por lo que no hemos podido identificarla con seguridad. Se le aprecia una P/...,(PI/TANO ?) y el troquel presenta cierta similitud con el de la cruz de nudos de Zumárraga -también superpuesta e ilegible-, esta última se acompaña con la marca de localidad de Vitoria. De ahí que la hayamos relacionado con este platero de la ciudad, pero no conocemos que se hayan conservado otros modelos similares en la platería vitoriana.

La pieza responde a modelos manieristas con pervivencias góticas -astil prismático- y elementos renacentistas como el pie y nudo. Incorpora las asitas del gollete, la forma y decoración que presenta son características del estilo manierista. Obra datable en el tercer cuarto del siglo.

A través del análisis de estas piezas podemos decir, que el platero Juan de Pitano y Bolívar presenta, en sus primeras obras, la influencia de los modelos góticos que había aprendido en el taller familiar, pero evoluciona con el paso del tiempo hacia formas y, sobre todo, ornamentación más moderna, de acorde con las corrientes imperantes de la orfebrería en el momento de elaboración de las obras.

Con el estudio de este artífice y sus obras nos hemos propuesto no sólo dar a conocer a este importante maestro platero vitoriano, sino demostrar su calidad en el oficio y sentido artístico, así como otros objetivos que en definitiva encierran mayor interés que el simple hecho de estudiar aisladamente a un platero. Analizado su obra damos a conocer un pequeño panorama artístico de la platería vitoriana de esa época, la cual no había sido estudiada hasta ahora. También queremos poner de manifiesto que los obradores vitorianos tuvieron una gran importancia desde finales del siglo xv y mantuvieron una considerable actividad durante todo el siglo xvI. 